\title{
Expression of frog virus 3 genes is impaired in mammalian cell lines Heather E Eaton ${ }^{1}$, Julie Metcalf ${ }^{2}$ and Craig R Brunetti*1
}

\author{
Address: ${ }^{1}$ Department of Biology, Trent University, Peterborough, ON, Canada and ${ }^{2}$ Department of Laboratory Medicine and Pathobiology, \\ University of Toronto, Toronto, ON, Canada \\ Email: Heather E Eaton - heathereaton@trentu.ca; Julie Metcalf - juliem@cogeco.ca; Craig R Brunetti* - craigbrunetti@trentu.ca \\ * Corresponding author
}

Published: 21 July 2008

Virology Journal 2008, 5:83 doi:10.1186/1743-422X-5-83

This article is available from: http://www.virologyj.com/content/5/l/83

(c) 2008 Eaton et al; licensee BioMed Central Ltd.

This is an Open Access article distributed under the terms of the Creative Commons Attribution License (http://creativecommons.org/licenses/by/2.0), which permits unrestricted use, distribution, and reproduction in any medium, provided the original work is properly cited.
Received: 28 May 2008

Accepted: 21 July 2008

\begin{abstract}
Frog virus 3 (FV3) is a large DNA virus that is the prototypic member of the family Iridoviridae. To examine levels of FV3 gene expression we generated a polyclonal antibody against the FV3 protein 75L. Following a FV3 infection in fathead minnow (FHM) cells $75 \mathrm{~L}$ was found in vesicles throughout the cytoplasm as early as 3 hours post-infection. While $75 \mathrm{~L}$ expressed strongly in FHM cells, our findings revealed no 75L expression in mammalian cells lines despite evidence of a FV3 infection. One explanation for the lack of gene expression in mammalian cell lines may be inefficient codon usage. As a result, 75L was codon optimized and transfection of the codon optimized construct resulted in detectable expression in mammalian cells. Therefore, although FV3 can infect and replicate in mammalian cell lines, the virus may not express its full complement of genes due to inefficient codon usage in mammalian species.
\end{abstract}

\section{Background}

Iridoviridae family members are large, icosahedral, double-stranded DNA viruses that are unique among eukaryotic virus genomes because they are both circularly permuted and terminally redundant [1]. The Iridoviridae family of viruses is comprised of five genera that can infect a variety of invertebrates (Iridovirus, Chloriridovirus) and ectothermic vertebrates (Lymphocystivirus, Ranavirus, Megalocytivirus) [2]. Specifically, Ranaviruses infect a variety of vertebrate hosts and have been isolated from fish, reptiles, and amphibians [3]. Frog virus 3 (FV3) is the type species of the genus Ranavirus and the best studied iridovirus at the molecular level. Although FV3 has not been isolated from fish, closely related viruses to FV3 including epizootic haematopoietic necrosis virus (EHNV) and Bohle virus (BIV) have both been previously isolated from a variety of fish species [4-6]. However, while FV3 is restricted to infecting a variety of amphibians and reptiles in vivo, fathead minnow (FHM) cells (fish) are highly susceptible to FV3 infections and are commonly used to culture the virus in vitro [7-9]. Therefore, FHM cells will be used to study the virus in a natural environment.

Although FV3 is unable to naturally infect any endothermic species, FV3 can infect and produce infectious virions in mammalian cell lines including human cell lines $[10,11]$ when cultured at $30^{\circ} \mathrm{C}[9]$. Mammalian cells will therefore be used to represent species that FV3 does not normally infect. Also, because of the ease with working in mammalian cell lines as compared to ectothermic cell lines, mammalian cell lines are often used to characterize FV3 genes and study virus replication. In order to further investigate FV3 infections in mammalian cell lines, we chose to examine the non-essential gene $75 \mathrm{~L}$, which is unique to the Ranavirus genus of the Iridoviridae family [12]. 75L, an 84 amino acid protein, has homology to cel- 
lular lipopolysaccharide-induced tumor necrosis factor- $\alpha$ factor (LITAF) [13] and is thought to play a role in virushost interactions [12].

In order to determine whether FV3-75L, a non-essential gene, is expressed in mammalian cells following a FV3 infection, the mammalian cell lines BGMK (green monkey) and HeLa (human), as well as an ectothermic cell line, FHM were infected with FV3 at a multiplicity of infection (MOI) of 1. FV3 was obtained from the American Type Culture Collection (ATCC; Manassas, VA) and was propagated on FHM cells (ATCC) grown in modified Eagle's medium (MEM; Invitrogen, Burlington, ON) supplemented with $10 \%$ fetal bovine serum (FBS; HyClone, Ottawa, ON), penicillin $(100 \mathrm{U} / \mathrm{mL})$ and streptomycin $(100 \mathrm{~g} / \mathrm{mL})$ at $30^{\circ} \mathrm{C}$. BGMK and HeLa cells were obtained from ATCC and maintained in Dulbecco's modified Eagle's medium (DMEM; HyClone) supplemented with $7 \%$ and $10 \%$ FBS respectively, $2 \mathrm{mM}$ L-glutamine, penicillin $(100 \mathrm{U} / \mathrm{mL})$, and streptomycin $(100 \mathrm{~g} / \mathrm{mL})$ at $37^{\circ} \mathrm{C}$ with $5 \% \mathrm{CO}_{2}$. Once infected with FV3, all cells were incubated at $30^{\circ} \mathrm{C}$. At various time points post-infection, cells were fixed in $3.7 \%$ paraformaldehyde in phosphate buffer saline (PBS) for 10 minutes, and permeabilized in a $0.1 \%$ Triton X-100 solution for 4 minutes. Indirect immunofluorescence (IF) was performed [14] using either a $1 / 200$ dilution of rabbit anti-75L antibody produced by GenScript (Piscataway, NJ), an affinity purified anti-peptide serum raised against the 75L peptide sequence CMDDKFTTLPCELED, or a $1 / 2000$ dilution of rabbit anti-FV3 antibody (V.G. Chinchar, University of Mississippi Medical Center). The primary antibodies were detected using goat anti-rabbit FITC (Jackson ImmunoResearch Inc. West Grove, PA) and images were captured using a Leica DM SP2 confocal microscope (Leica, Wetzlar, Germany). Images were assembled using Adobe Photoshop (Adobe, San Jose, CA).

In FHM cells, the anti-FV3 serum was able to detect antigen as early as 3 hours post-infection (Figure 1:A). In addition, 75L expression was also detectable in FHM cells starting at 3 hours post-infection and expression increased as the infection progressed (Figure 1:B). In contrast, expression of FV3 in HeLa and BGMK cells was not detectable until 16 hours post-infection (Figure 1:C,E) and no detectable 75L expression was observed in these cell lines even as late as 32 hours post-infection (Figure 1:D,F). Therefore, although a FV3 infection was detected in all three cell lines, 75L, a non-essential gene only expressed in FHM cells, an ectothermic cell line.

Although we demonstrated that FV3 can infect BGMK cells, we wanted to know whether FV3 produced infectious virions. BGMK cells were either mock infected or infected with FV3 at an MOI of 1 and harvested 48 hours later when cytopathic effects were seen. The cells were scraped, centrifuged for 5 minutes, and re-suspended in $100 \mu \mathrm{L}$ of DMEM (HyClone). Following three freezethaws, BGMK cells were inoculated with $1 \mu \mathrm{L}$ of the resulting suspension and were fixed 48 hours later. IF was performed using rabbit anti-FV3 antibody (V.G. Chinchar) and goat anti-rabbit FITC (Jackson ImmunoResearch Inc). Following the secondary antibody, cells were washed several times in PBS, and incubated in To-PRO-3 (Molecular Probes, Eugene, OR) for seven minutes diluted 1/10,000 in $\mathrm{dH}_{2} \mathrm{O}$. The cells were washed with PBS and fluorescence was detected using a Leica DM SP2 confocal microscope (Leica, Wetzlar, Germany). Images were assembled using Adobe Photoshop (Adobe, San Jose, CA). No FV3 expression was detected in mock infected cells (Figure 2:A) while plaques (data not shown) and high levels of FV3 protein were detected after 48 hours of infection (Figure 2:B), indicating that FV3 can produce infectious virions in BGMK cells.

Since 75L was not expressed in mammalian cell lines such as BGMK and HeLa cells following a FV3 infection, we wanted to investigate whether this was a property of the $75 \mathrm{~L}$ gene or a defect in viral expression of 75L. Therefore, we generated a C-terminal myc-tagged FV3-75L. In order to generate FV3 DNA for use in PCR, FHM cells were infected with FV3 at a MOI of 0.1 . When cytopathic effects were observed, cells were harvested and re-suspended in $400 \mu \mathrm{L} \mathrm{dH} \mathrm{H}_{2} \mathrm{O}$. Cells were freeze-thawed three times and an equal volume of phenol:chloroform was added and the aqueous phase was transferred to a fresh tube and $10 \%(\mathrm{v} / \mathrm{v}) 5 \mathrm{M}$ sodium acetate and $20 \%(\mathrm{v} / \mathrm{v})$ ethanol $(100 \%)$ was added. Following a 15 minute incubation on ice, DNA was pelleted by centrifugation and $10,000 \times \mathrm{g}$ for 10 minutes. DNA was air dried and re-suspended in $\mathrm{dH}_{2} \mathrm{O}$. A $50 \mu \mathrm{L}$ reaction mixture containing $10 \mathrm{ng}$ of DNA from virally infected cells, $1 \times$ PCR buffer (Invitrogen), 3.0 $\mathrm{mM} \mathrm{MgCl}_{2}$ (Invitrogen), $0.1 \mathrm{mM}$ dNTPs, $0.2 \mathrm{mM}$ of FV375L-forward (5'-AAGCTTATTA AAGATGGACGACAAG3') and FV3-75L-reverse (5'CTCGAGCTACAGATCTTCTTCAGAAATAAGTTTTTGTTCTAAAATTTTGTA CACAAACAC-3'), and $2.5 \mathrm{U}$ of Taq DNA polymerase $5 \mathrm{U} / \mu \mathrm{L}$ (Invitrogen) was used to amplify FV3-75L and add a myc tag to the $\mathrm{C}$ terminus using the following cycling conditions: $94^{\circ} \mathrm{C}$ for 30 seconds, $52^{\circ} \mathrm{C}$ for 30 seconds, $72^{\circ} \mathrm{C}$ for 90 seconds for 30 cycles. The resulting product was cloned into the eukaryotic expression vector pcDNA3.1 (Invitrogen). BGMK and FHM cells were grown to $80 \%$ confluence on $22 \mathrm{~mm}$ coverslips in a 6 -well plate. The cells were transfected with $5 \mu \mathrm{g}$ of FV375L DNA using a calcium phosphate mediated transfection protocol [15]. Twenty-four hours post-transfection, the cells were fixed and processed for IF using mouse antimyc antibody (Roche, Indianapolis, IN) to detect $75 \mathrm{~L}$ and 


\section{Time post-infection}
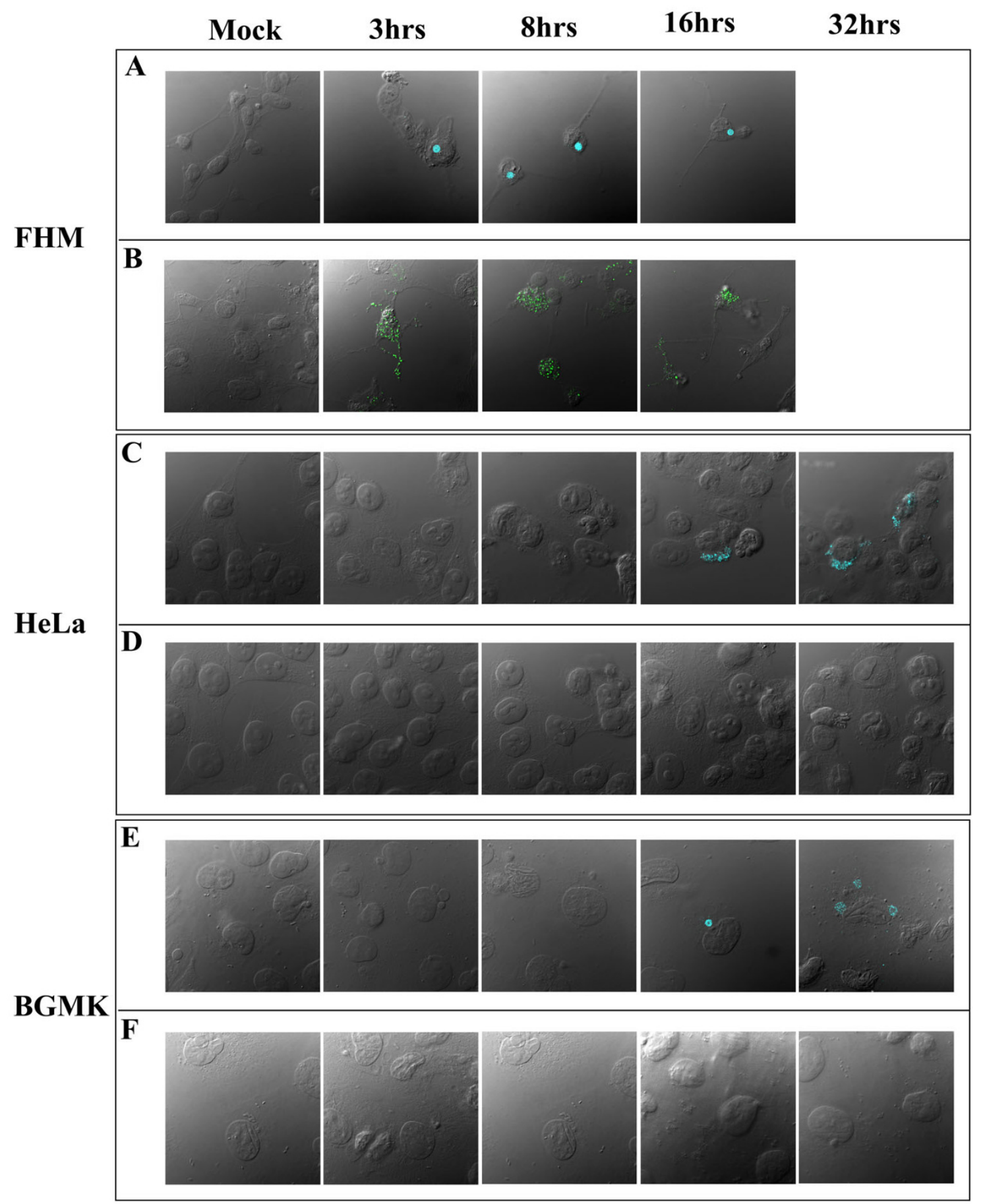

Figure I

FV3 infected BGMK and HeLa cells do not express the gene 75L. FHM, HeLa, and BGMK cells were infected with FV3 at an $\mathrm{MOI}$ of I. At $0,3,8,16$, and 32 hours post-infection, cells were fixed and a FV3 infection was detected using anti-FV3 antibodies (blue: A, C, E) and 75L was detected using anti-FV3-75L antibodies (green: B, D, F). No images of FHM cells at 32 hours were taken as the cells had succumbed to infection. Cells were visualized using DIC and indirect immunofluorescence images were captured on a laser scanning confocal microscope. 

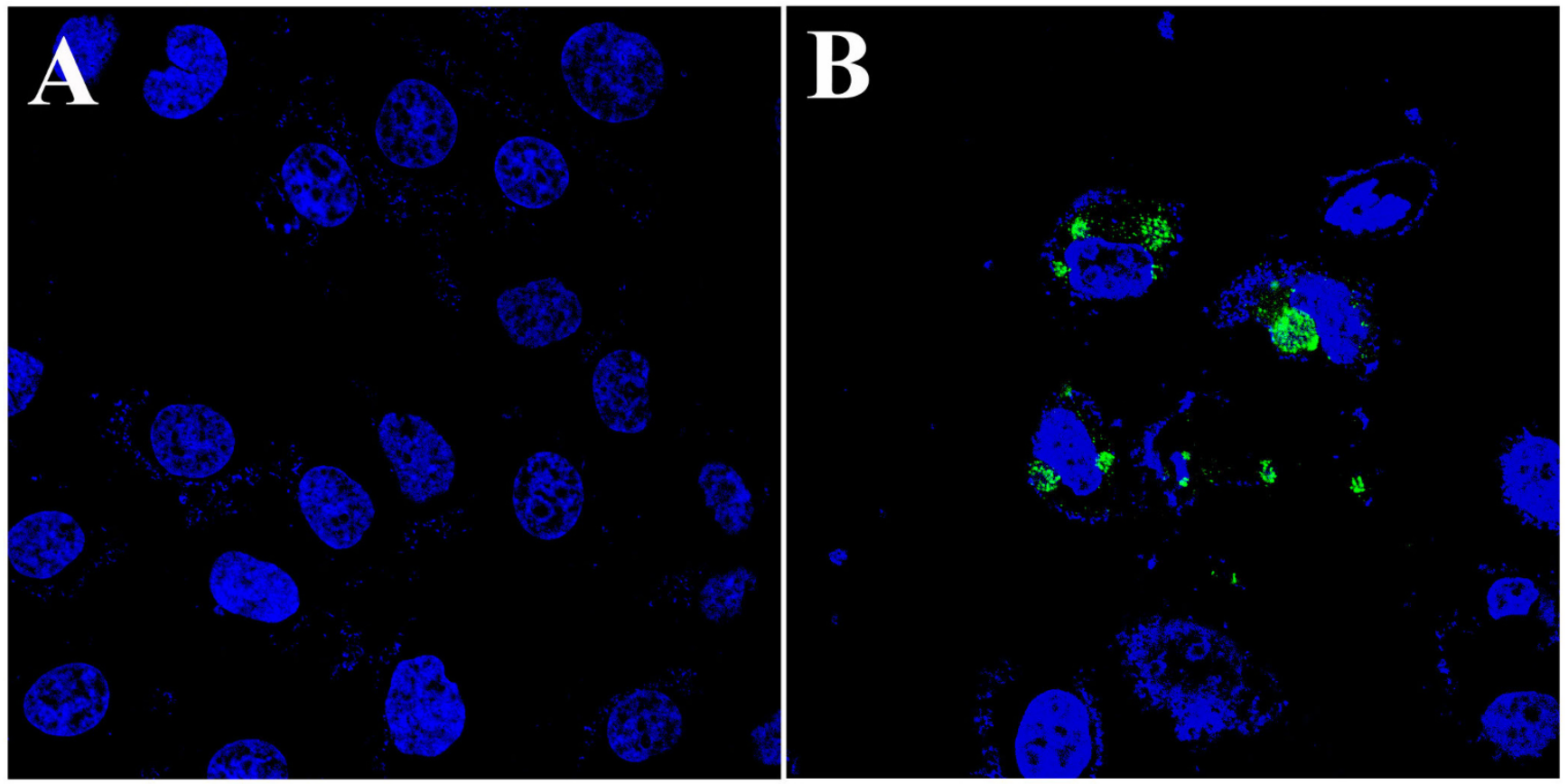

Figure 2

FV3 produces infectious virions in BGMK cells. BGMK cells were mock infected (A) or infected with FV3 at any MOI of I (B). 48 hours post-infection cells were harvested and virus was released. The BGMK produced virus was subsequently applied to BGMK cells and 48 hours later and the cells were fixed. FV3 was detected using anti-FV3 antibodies (green) and nucleus was visualized with ToPRO-3 (blue).

goat anti-mouse FITC antibodies (Jackson ImmunoResearch Inc.).

Transfection of FV3-75L in BGMK cells resulted in an absence of expression 24 hours post-transfection (Figure 3:A). This was consistent with the absence of 75L expression as a result of a FV3 infection in BGMK cells. Therefore, the lack of detectable 75L expression may be a property of the 75L gene and not a defect in viral driven gene expression. It is common for transfected viral genes to be expressed poorly in primate and mammalian cell lines. For instance, transfection of many poxvirus genes into mammalian cells results in low levels of expression [16]. Several reasons may account for this phenomenon including the use of cryptic slice sites with the pre-mRNA, mRNA instability motifs, and RNA polymerase II termination sites [16]. Another reason for poor levels of expression of viral genes may be inefficient codon usage [16-19]. The frequency that a given codon appears in a genome varies significantly between different organisms $[20,21]$. In order to achieve high levels of gene expression, it is important that the specific codon frequency within the gene matches that of the desired expression system. It is possible that the FV3-75L gene is optimized for expression in poikilothermic species, but not for mammalian cell lines. To determine if inefficient codon usage was respon- sible for the inability to detect FV3-75L in BGMK cells, a C-terminal myc-tagged construct, $75 \mathrm{~L}$ was codon optimized (CO75L; GenScript) for Homo sapiens to achieve maximum expression in mammalian cell lines. Codon optimization corrects a variety of issues associated with low protein production including the replacement of infrequently used codons with those preferred by the desired host, the elimination of problematic codons, the elimination of cryptic splice sites, and the disruption of some regulatory elements that normally may result in a decrease in protein production. A comparison of the original nucleotide sequence of 75L [Gene ID 2947794] and CO75L is shown (Figure 3:C). CO75L was cloned into the eukaryotic expression vector pcDNA3.1 (Invitrogen) and transfected into BGMK cells and twenty-four hours posttransfection cells were fixed and indirect IF was used to detect 75L (mouse anti-myc and goat anti-mouse FITC conjugated antibodies). Transfection of CO75L resulted in high levels of expression compared to undetectable expression for the non-codon optimized gene (Figure 3:A,B). Expression of 75L in both BGMK and FHM cell lines revealed similar staining throughout the cytoplasm of the cell (Figure 1:B versus $3: \mathrm{B}$ ). The staining appears to be vesicular but may represent viral sites of replication. Therefore, the absence of 75L expression by FV3 in mammalian cells is due to inefficient codon usage. 


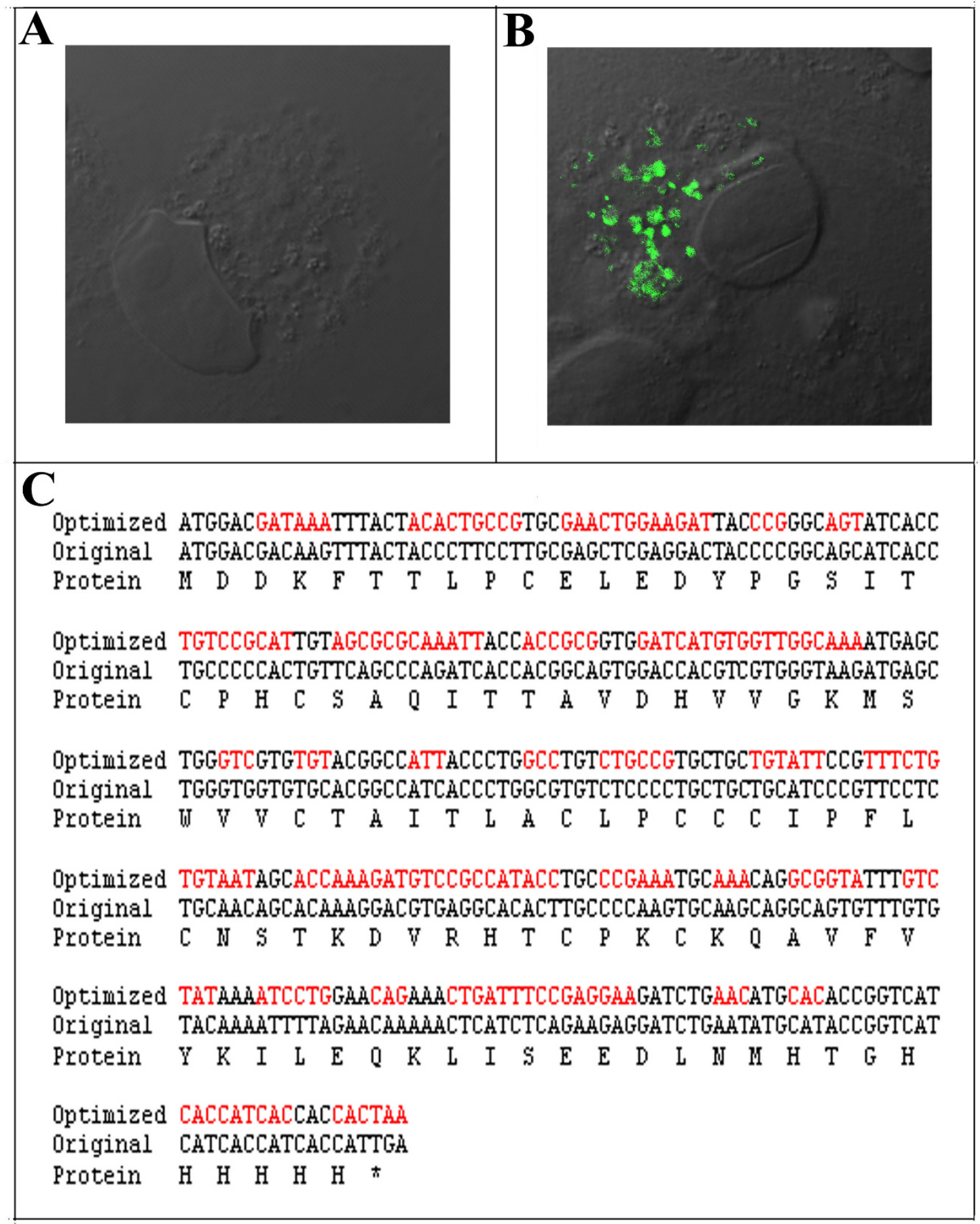

Figure 3

Codon optimized 75L expresses in BGMK cells. A FV3-75L construct tagged with a C-terminal myc tag under the control of a CMV promoter (A) or a codon optimized construct (B) was transfected into BGMK cells. Twenty-four hours posttransfection cells were fixed and indirect immunofluorescence was performed to detect $75 \mathrm{~L}$ (anti-myc:green) and differential interference contrast (DIC) was used to visualize the cell. Images were captured on a laser scanning confocal microscope. (C) The optimized sequence is shown above the original $75 \mathrm{~L}$ sequence, with altered nucleotides shown in red. The corresponding amino acids are shown on the bottom row and are the same for both the original and optimized sequence. 
This data demonstrates that at least one FV3 gene does not produce detectable proteins in mammalian cell lines. We believe that the lack of $75 \mathrm{~L}$ expression is not unique to this gene as we have been unable to express a variety of FV3 genes including FV3 5R, 13R, 28R, and 29R in mammalian cell lines (data not shown). Although we have not yet shown that these genes are unable to express because of inappropriate codon usage in mammalian cell lines, the research conducted here suggests that poor codon usage is a likely reason for the lack of expression.

The consequence of codon bias in FV3 and perhaps the entire Iridoviridae family is that only a subset of all viral genes may be expressed in mammalian cell lines. However, essential viral genes must express in mammalian cell lines since the virus is able to infect and successfully replicate in many cell lines, including rodent, human, and simian cell lines (Figure 2) $[10,11]$. Although essential viral genes must be expressed, non-essential genes that are not directly involved in replication of the virus may or may not be expressed in mammalian cell lines. The possibility therefore exists that virus-host interaction may differ in mammalian cells as compared to ectothermic cell lines because the entire subset of viral genes is not expressed in mammalian cells.

Therefore, when investigating the biological properties of FV3 and perhaps other iridoviruses, it is critical that these studies be performed in ectothermic cells otherwise the entire complement of viral genes may not be expressed. In addition to the critical finding that non-essential genes may not be expressed in mammalian cells, we have also demonstrated that this expression defect can be reversed through codon optimization of the viral genes. Thus, for biochemical studies relying on the use of mammalian cell lines, codon optimization may be a solution for achieving higher levels of expression of iridovirus genes that express poorly in mammalian systems. This work has also provided a means for further characterization of the function of $75 \mathrm{~L}$.

\section{Competing interests}

The authors declare that they have no competing interests.

\section{Authors' contributions}

HEE performed the research and helped to draft the manuscript. JM helped perform the research. CRB conceived the study and participated in its design and coordination and helped draft the manuscript. All authors read and approved the final manuscript.

\section{Acknowledgements}

This work is supported by Discovery Grants (Natural Science and Engineering Research Council (NSERC) of Canada) to C.R.B. H.E.E. is the recip- ient of a NSERC postgraduate scholarship. We thank Dr. V.G. Chinchar of the University of Mississippi Medical Center for providing the anti-FV3 antibodies.

\section{References}

I. Goorha R, Murti KG: The genome of frog virus 3, an animal DNA virus, is circularly permuted and terminally redundant. Proc Natl Acad Sci USA 1982, 79(2):748-752.

2. Chinchar VG, Essbauer S, He JG, Hyatt A, Miyazaki T, Seligy V, Williams T: Family Iridoviridae. In Virus Taxonomy Eighth report of the International Committee on Taxonomy of Viruses Edited by: Fauquet CM, Mayo MA, Maniloff J, Desselberger U, Ball LA. San Diego, Academic Press; 2005: 145-162.

3. Williams T, Chinchar VG, Darai G, Hyatt A, Kalmakoff J, Seligy V: Virus taxonomy: The classification and nomenclature of viruses. In Seventh report of the International Committee on the Taxonomy of Viruses Edited by: van Regenmortel MHV, Bishop DHL, Carstens EB, Estes MK, Lemon SM, Maniloff J, Mayo MA, McGeoch DJ, Pringle CR, Wickner RB. San Diego, Academic Press; 2000: 167-182.

4. Langdon JS: Experimental transmission and pathogenicity of epizootic haematopoetic necrosis virus (EHNV) in redfin perch, Perca fluviatilis L. and II other teleosts. Journal of Fish Diseases 1989, I 2:295-310.

5. Langdon JS, Humphrey JD, Williams LM, Hyatt AD, Westbury HA First virus isolation from Australian fish: an iridovirus-like pathogen from redfin perch, Perca fluviatilis. Journal of Fish Diseases 1986, 9:263-268.

6. Moody NJG, Owens L: Experimental demonstration of the pathogenicity of a frog virus, Bohle iridovirus, for a fish species, barramundi Lates calcarifer. Diseases of Aquatic Organisms 1994, 18:95-102.

7. Naegele RF, Granoff A: Viruses and renal carcinoma of Rana pipiens. XI. Isolation of FV3 temperature-sensitive mutants; complementation and genetic recombination. Virology |97|, 44:286-295.

8. Goorha R: Frog virus 3 DNA replication occurs in two stages. Journal Of Virology 1982, 43:519-528.

9. Gravell M, Granoff A: Virus and renal adenocarcinoma of Rana pipiens: IX. The influence of temperature and host cell on replication of frog polyhedral cytoplasmic deoxyribovirus (PCDV). Virology 1970, 41:596-602.

10. Granoff A: Viruses of amphibia. Current Topics in Microbiology and Immunology 1969, 50:107-137.

II. Chinchar VG: Ranaviruses (family Iridoviridae): emerging coldblooded killers. Archives of Virology 2002, I47(3):447-470.

12. Tan WG, Barkman TJ, Chinchar VG, Essani K: Comparative genomic analyses of frog virus 3 , type species of the genus Ranavirus (family Iridoviridae). Virology 2004, 323(I):70-84.

13. Myokai F, Takashiba S, Lebo R, Amar S: A novel lipopolysaccharide-induced transcription factor regulating tumor necrosis factor alpha gene expression: Molecular cloning, sequencing, characterization, and chromosomal assignment. Proc Natl Acad Sci USA 1999, 96(8):45 I8-4523.

14. Eaton HE, Metcalf J, Brunetti CR: Characterization of the promoter activity of a poxvirus conserved element. Canadian Journal of Microbiology 2008, 54:483-488.

15. Sambrook J, Russell DW: Molecular Cloning A Laboratory Manual. Volume 3. Third edition. Cold Spring Harbor, Cold Spring Harbor Laboratory Press; $200 \mathrm{I}$.

16. Barrett JW, Sun Y, Nazarian SH, Belsito TA, Brunetti CR, McFadden $\mathrm{G}$ : Optimization of codon usage of poxvirus genes allows for improved transient expression in mammalian cells. Virus Genes 2006, 33:15-26.

17. Bradel-Tretheway BG, Zhen Z, Dewhurst S: Effects of codon-optimization on protein expression by the human herpesvirus 6 and 7 U5I open reading frame. Journal of Virological Methods 2003, III:145-156.

18. Mossadegh M, Gissmann L, Muller M, Zentgraf J, Alonso A, Tomakidi P: Codon optimization of the human papillomavirus I I (HPV II) LI genes leads to increased gene expression and formation of virus-like particles in mammalian epithelial cells. Virology 2004, 326:57-66. 
19. Nguyen KL, Hanc M, Akari H, Miyagi E, Peischla EM, Strebel K, Bour S: Codon optimization of the HIV-I vpu and vif genes stabilizes their mRNA and allows for highly efficient Rev-independent expression. Virology 2004, 31 9:163-175.

20. Grantham R, Gautier C, Gouy M, Jacobzone M, Mercier R: Codon catalog usage is a genome strategy modulated for gene expressivity. Nucleic Acid Research 198I, 9(I):r43-r74.

21. Grantham R, Gautier C, Gouy M, Mercier R, Pave A: Codon catalog usage and the genome hypothesis. Nucleic Acid Research 1980, 8(1):r49-r62.

Publish with Bio Med Central and every scientist can read your work free of charge

"BioMed Central will be the most significant development for disseminating the results of biomedical research in our lifetime. " Sir Paul Nurse, Cancer Research UK

Your research papers will be:

- available free of charge to the entire biomedical community

- peer reviewed and published immediately upon acceptance

- cited in PubMed and archived on PubMed Central

- yours - you keep the copyright

Submit your manuscript here:

http://www.biomedcentral.com/info/publishing_adv.asp 